\title{
REDES DE APRENDIZADO EM SISTEMAS COMPLEXOS DE PRODUÇÃO
}

\section{RESUMO}

Procura-se demonstrar neste artigo que o arranjo inter-organizacional típico dos Sistemas Complexos de Produção é o de rede de firmas, marcada por uma forte especialização dos agentes que a compõem e uma intensa complementaridade entre eles. Nesse tipo de arranjo, a empresa que exerce a governança da rede busca estimular o processo de eficiência coletiva. Essa busca, por sua vez, dada a freqüente heterogeneidade dos agentes, termina por induzir a rede de firmas a transformar-se em uma rede de aprendizado. Apesar do conhecimento sobre essas redes ser ainda muito precário, podem-se levantar, com base na literatura revisada e no exame de uma rede de aprendizado em implantação no Brasil, os seguintes aspectos: ela precisa ter um propósito claro, traduzível em uma meta a ser atingida por intermédio do processo de aprendizado; é necessário criar uma estrutura, que pode tender ao virtual, e definir recursos e mecanismos a serem utilizados em sua implantação e sustentação; e deve-se tentar prever, a partir de outras experiências, as inevitáveis dificuldades que surgirão no planejamento e operacionalização dessas redes.

\section{Francisco Teixeira}

Doutor em Política Industrial e Tecnológica pela University of Sussex e Professor da UFBA.

E-mail: teixeira@ufba.br

\section{Oswaldo Guerra}

Doutor em Economia pela Unicamp e Professor da UFBA.

E-mail: oguerra@ufba.br

\begin{abstract}
This paper is an attempt to demonstrate that firm networks is the typical institutional arrangement of Complex Production Systems, marked by a strong specialization of participating agents and an intense complementarity among them. In this type of arrangement, the firm in charge of network governance needs to stimulate the search for collective efficiency. This search, in turn, given the frequent heterogeneity among agents, ends up inducing the formation of a learning network. In spite of the fact that the accumulated knowledge on learning networks is precarious, it is possible to recommend, based on a literature review and the example of a learning network being implemented in Brazil, the following points: the network needs a clear purpose translatable in a target to be met by a learning process; it is necessary to create a structure, which can be virtual, and define resources and mechanisms to be used in the implementation and support of the network; it should be tried to forecast, departing from other experiences, the inevitable difficulties that would come up in the design and implementation of such networks.
\end{abstract}

PALAVRAS-ChAVE Sistemas Complexos de Produção, redes de firmas, redes de aprendizado, cadeia de suprimento.

KEY WORDS Complex Production Systems, firms networks, learning network, supply chain. 


\section{INTRODUÇÃo}

Os Sistemas de Produção Convencionais, em geral associados à produção em massa, são, sem dúvida, os que mais têm recebido atenção dos estudiosos no campo da organização industrial quando estes examinam, por exemplo, as transformações nas estruturas de mercado, os limites para a expansão da firma, a formulação e a coerência das estratégias empresariais, e os processos de inovação tecnológica e organizacional.

Recentemente, alguns autores (Mowery e Rosenberg, 1982; Miller et al., 1995; Davies, 1997; Hobday, 1998) têm se debruçado sobre os chamados Sistemas Complexos de Produção (CoPS), responsáveis por produtos ou sistemas intensivos em engenharia, de alto custo e feitos por encomenda, como é o caso de simuladores de vôo, helicópteros, plantas nucleares, submarinos, plataformas de petróleo etc. É evidente que não se deseja colocar esses exemplos em um mesmo patamar de complexidade. O que os une é o fato de possuírem um grande número de componentes customizados e requererem um elevado nível de abrangência de conhecimentos e de capacitações.

Pesquisas realizadas em alguns desses CoPS sugerem que o arranjo interorganizacional típico em que se apresentam é o de rede de firmas, marcada por uma forte especialização dos agentes que compõem suas cadeias de suprimentos - supply chain - e uma intensa complementaridade entre eles, o que atenua ou elimina rivalidades potenciais. A freqüente heterogeneidade desses agentes, em termos de capacitações produtiva, tecnológica e organizacional, termina por estimular essa rede de firmas a transformar-se em uma rede de aprendizado, entendida enquanto um pool social de conhecimentos e informações que circulam entre seus membros, gerando fortes externalidades positivas.

Quais as principais características teóricas desses CoPS e das redes de firmas que neles são configuradas? Que argumentos justificam a transformação de uma rede de firmas em uma dada cadeia de suprimentos, em uma rede de aprendizado voltada para a obtenção de ganhos competitivos? Reconhecendo que o aprendizado em rede não é uma característica natural de qualquer tipo de cadeia de suprimentos, quais os mecanismos que podem ser usados para sua formação e quais as dificuldades para que ela seja efetivada e desenvolvida?

O principal objetivo deste artigo é buscar respostas para tais questões, à luz da revisão teórica empre- endida e da análise da rede de aprendizado que está sendo implantada entre os participantes da cadeia de suprimentos de equipamentos e serviços para a construção, montagem, instalação, operação e manutenção de sistemas de produção de petróleo offshore um caso típico de CoPS - no Brasil.

Além desta introdução e das considerações finais, este artigo possui três seções. Na primeira, algumas características teóricas dos CoPS e das redes de firmas serão explicitadas. Na segunda, apresentam-se os argumentos que justificam a transformação de uma rede de firmas em uma rede de aprendizado, sua relevância, as barreiras que dificultam a entrada das organizações nesse tipo de arranjo, os requisitos que precisam ser observados para que ela constitua-se e os processos considerados centrais em sua operação. $\mathrm{Na}$ terceira, com a descrição e análise do processo de criação de uma rede de aprendizado no país, será possível revisar os principais temas abordados nas duas seções anteriores.

\section{CoPS E REDES DE FIRMAS}

Em termos de oferta, um CoPS é fornecido por uma unidade de produção, seja ela uma firma ou uma organização baseada em um projeto temporário envolvendo muitas firmas, a exemplo de uma Sociedade de Propósito Específico - SPE. Quanto à demanda, um CoPS é comprado por um único usuário ou um pequeno número de usuários.

No que diz respeito às características do produto e do processo produtivo, os CoPS apresentam inter-relações complexas entre suas peças e componentes, altos custos unitários, pequenos lotes de produção, grande diversidade de capacitações e conhecimentos requeridos para sua montagem, além de serem elaborados de acordo com requisitos bem especificados pelo usuário - o que reflete a customização associada a seu processo de produção.

Embora em qualquer arquitetura de produção seja necessária uma dada hierarquia de sistemas e componentes, uma outra característica intrínseca dos CoPS é a complexidade dessa hierarquia. Um projeto CoPS, como o de uma plataforma de petróleo, é geralmente elaborado por uma coalizão de organizações e envolve uma série de fases, incluindo a preparação da proposta para licitação, a conceituação e detalhamento do design, a fabricação, entrega e instalação, a inovação pós-produção, a manutenção e, algumas vezes, a 
desativação do sistema de produção encomendado.

Essas características, descritas por Hobday (1998), interferem diretamente nos processos de inovação dos CoPS. Elas forçam, por exemplo, uma forte interação entre os vários agentes envolvidos no desenvolvimento de produtos. Sem desejar criar nenhum tipo de abordagem dicotômica entre os CoPS e os sistemas de produção em massa, pois entre esses extremos existem outros tipos de sistemas de produção, pode-se dizer que, ao contrário do modelo de produção em massa, onde a trajetória tecnológica é fortemente mediada pela seleção de mercado, nos CoPS essa trajetória é, fundamentalmente, pré-acordada pelos integrantes do sistema.

Isso, por sua vez, eleva o grau de importância tanto das etapas de definição dos projetos, quanto da tarefa de coordenação do processo inovativo. O foco em design e desenvolvimento de produtos é outra marca registrada desse processo. Os produtos ou processos desenvolvidos nos CoPS tendem a apresentar uma crescente complexidade ao longo do tempo, o que implica, concomitantemente, uma elevação da demanda por requisitos de performance, capacitação e confiabilidade.

Boa parte dos conhecimentos e habilidades necessários para tal desenvolvimento e capacitação tecnológica é de natureza tácita, cuja codificação torna-se bastante problemática. Isso fortalece os vínculos e a interdependência dos agentes participantes, criando a necessidade de uma integração de competências em sistemas. Nesses vínculos, que explicitam o alto grau de envolvimento entre produtor e usuário, este último é responsável por uma série de avanços incrementais a partir do projeto inicial.

Por tudo isso, a estrutura em rede tem se tornado o arranjo interorganizacional típico dos CoPS. Esse tipo de arranjo define, ao mesmo tempo, a configuração e a coordenação do processo inovativo e da evolução industrial. Dada a especificidade dos bens e serviços que compõem um CoPS, o relacionamento das poucas grandes firmas presentes é primordialmente de longo prazo e envolve contratos de alto valor, o que dá uma certa estabilidade à rede.

A existência de poucas grandes firmas, tanto do lado dos usuários como, e principalmente, do lado dos fornecedores, inocula nos mercados de CoPS os seguintes traços constitutivos: pequeno número de grandes transações; determinação de preços extra-mercado; grande influência da política de compras das firmas; e, não raro, intervenção direta e/ou indireta do Esta- do, com sua política de compras ou de sistemas regulatórios, haja vista o caráter estratégico dos setores envolvidos com CoPS.

Se o arranjo institucional típico dos CoPS é a estrutura em rede de firmas, cabe examiná-la melhor. As redes podem ser de dois tipos: verticais e horizontais. Nas verticais, observa-se a articulação de um conjunto de fornecedores e distribuidores por uma empresa coordenadora que exerce considerável influência sobre a ação de tais agentes. Nesse caso, ocorre a perda de autonomia relativa dos agentes, na medida em que sua identidade dissolve-se no interior do conjunto. Na perspectiva da empresa coordenadora, a rede assegura o controle estratégico da cadeia produtiva. Já nas redes horizontais, empresas concorrentes estabelecem alianças entre si, dando origem a um formato organizacional que se justifica pelas vantagens da centralização de recursos para a execução de determinadas atividades comuns. Aqui, a autonomia estratégica dos atores é mantida (Mazzali e Costa, 1997).

Em termos de teoria dos custos de transação, como apresentada por Williamson (1985), a cooperação presente nas redes é vista como uma forma de organização intermediária, situada entre a firma integrada verticalmente e o mercado. A cooperação implícita nas redes permitiria a superação do oportunismo, enquanto código de conduta que orienta os comportamentos individuais e a consolidação de um ambiente intrarede baseado na confiança mútua entre os agentes.

A disseminação de princípios de confiança mútua seria explicada pela presença dos seguintes elementos: minimização da incerteza comportamental associada a práticas oportunistas; eliminação de custos contratuais vinculados à montagem de arranjos que incorporam mecanismos defensivos de monitoração das condutas; otimização da divisão do trabalho no âmbito da rede, adequando-se as escalas de produção e evitando-se a duplicação de esforços; e viabilização de transferências de informações de natureza tácita.

A despeito dos importantes subsídios aportados por essa teoria como explicação para o comportamento da firma e os limites para sua expansão, uma análise sobre a formação de redes de firmas não pode omitir outras dimensões-chave da atividade corporativa, que se somam àquelas relacionadas à alocação de recursos. Ao não analisar, por exemplo, o conhecimento e a tecnologia, a teoria dos custos de transação desconsidera aspectos cruciais do processo de decisão da empresa, particularmente os associados à aprendiza- 
gem e à inovação. Ao não contextualizar historicamente a trajetória de crescimento da firma, não se leva em conta a importância vital das decisões estratégicas tomadas no passado - particularmente as vinculadas com a expansão produtiva - sobre o futuro da firma, tampouco os inevitáveis custos de adaptação e de aprendizagem em que a firma incorre quando decide internalizar atividades (Chandler, 1992).

Como resultado, a concepção de eficiência é estática, inerente às condições iniciais da análise, e a firma é vista como uma mera combinadora de fatores de produção genéricos disponíveis ex-ante obtidos por meio de relações de troca no mercado, sendo seu objetivo minimizar os custos de transação envolvidos nessas relações (Chandler, 1992; Pondé, 1993; Britto, 1994; Mazzali e Costa, 1997).

Em vista disso, a problemática em investigação, a formação de redes de firmas em sistemas complexos de produção, pode ser melhor examinada no âmbito da teoria evolucionista e de competências dinâmicas de Nelson e Winter (1982), Teece $(1988,1998)$ e Dosi, Teece e Winter (1992) e/ou no da resource based theories de Penrose (1959) e seus seguidores, dos quais destaca-se Richardson (1972). Para essas abordagens, que possuem forte complementaridade, as atividades de produção de uma empresa são vistas como um processo de criação de recursos, no qual o conhecimento técnico e organizacional é crucial para a transformação de recursos genéricos em específicos. Em outras palavras, dinamicamente as firmas podem ser vistas como dispositivos de aprendizagem que conferem especificidade aos recursos.

A aprendizagem, por sua vez, resultaria da oportunidade que a atividade produtiva ofereceria para a experimentação, o aperfeiçoamento, a consolidação de procedimentos e a identificação de novos métodos. Essa aprendizagem, ao longo do tempo, permitiria que a firma criasse competências. A noção de competência associa-se, portanto, à capacidade das firmas agregarem a seu portfólio de recursos intangíveis um conjunto de conhecimentos especializados, obtidos ao longo do tempo, como resultado das condutas empresariais adotadas e dos recursos alocados. Tais conhecimentos, todavia, não são suficientemente amplos, de modo a permitir realizar todas as atividades necessárias a seu processo produtivo com a mesma eficiência. Sendo assim, as firmas terminam por especializar-se, isto é, por aprofundar o conhecimento em determinadas áreas associadas à sua base tecnológica e/ou área de mercado, constituindo o que Penrose
(1959) chamou de área de especialização.

A combinação de competência e especialização está, de certo modo, por trás da idéia de capacitação organizacional que, como se sabe, é chave em Chandler (1990) e pode ser assim sintetizada: reuniria a capacitação estratégica - de responsabilidade da alta gerência -, a capacitação funcional - a cargo da gerência média, em conjunto com a baixa gerência e o restante da força de trabalho - e os ativos físicos da organização. Para o autor, somente quando as habilidades das gerências superior, média e baixa e do restante da força de trabalho foram cuidadosamente coordenadas e integradas com os ativos físicos, por intermédio da "mão visível" da hierarquia, as empresas puderam crescer em seus mercados tradicionais e em novos mercados.

Nesse processo de crescimento, nenhuma empresa domina a totalidade dos conhecimentos necessários para a realização do conjunto de atividades ao longo de sua cadeia produtiva. Todas elas devem, no mínimo, considerar a conveniência de especializar-se em algumas atividades e apoiar-se nas competências de outras empresas. É nesse contexto que Richardson (1972) destaca a importância vital da interdependência e cooperação entre empresas e sublinha sua diferença em relação a Williamson (1985).

Para aquele, a cooperação em rede não deve ser vista como uma forma de organização intermediária entre firma e mercado, definida a partir de uma avaliação dos custos das transações de compra e venda. O entendimento dessa relação requer uma análise mais ampla, exigindo que se examine a geração de valor ao longo do processo de produção. A produção, para Richardson (1972), reúne múltiplas atividades, sendo que, para a execução de algumas delas, necessitase de competências similares, em oposição às designadas como complementares. Desse modo, as empresas tenderiam a estruturar-se em torno das atividades que requerem o uso de competências similares, recorrendo a outras empresas à medida que elas possuam competências não-similares às suas. Assim, a cooperação surgiria da necessidade de coordenar atividades não-similares e fortemente complementares.

Os evolucionistas, a exemplo de Dosi, Teece e Winter (1992) e Teece (1998), ao trabalharem com a idéia de coerência estratégica, também apoiam-se, de certo modo, em Penrose (1959), quando ela sublinha o respeito que as firmas devem ter por sua base tecnológica e/ou área de mercado antes de se envolverem com movimentos de integração e diversificação 
produtiva. A coerência estratégica delimitaria as fronteiras da grande empresa e, ao ser mantida, possibilitaria o exercício do aprendizado ao longo do tempo, criando competências nucleares, entendidas como "um conjunto de capacitações tecnológicas diferenciadas e de rotinas organizacionais que constituem a fonte de vantagem competitiva da firma em um ou mais ramos de negócios" (Dosi, Teece e Winter, 1992, p. 197).

O exposto até aqui sugere que o estreitamento do contato entre empresas, seus fornecedores, distribuidores e mesmo concorrentes, exigido pelos CoPS, por um lado, reduz o repertório de ações da empresa individual, mas, por outro, faz com que ganhe em flexibilidade. A forte especialização dos diversos agentes integrantes de sua rede de firmas aumenta a complementaridade entre eles, atenuando ou eliminando as rivalidades potenciais. A redução dos riscos de rivalidade e o reforço da complementaridade especializam os parceiros no interior da rede, reforçando sua coerência e garantindo sua estabilidade.

Essa mesma abordagem sugere também a necessidade de aprofundar a investigação sobre os CoPS e as redes de firmas, para que se possa enriquecer o entendimento sobre a dinâmica concorrencial e as estratégias empresariais. Isto porque a unidade básica de análise para a compreensão desses temas deixa de limitar-se à firma individual e passa a envolver as redes de firmas. Nos sistemas complexos de produção, colaboração na elaboração de propostas para licitações e capacidade na execução conjunta de projetos são competências básicas para seus produtores. Como a competição dá-se entre projetos e não entre firmas individuais, melhorias isoladas em uma firma individual, apesar de importantes, podem ter apenas um pequeno efeito na competitividade e performance do projeto. Desse modo, uma efetiva competitividade requer a otimização de procedimentos do conjunto de firmas envolvidas com tais projetos. Ou seja, a eficiência coletiva sobrepõe-se à eficiência individual.

\section{REDES DE FIRMAS E REDES DE APRENDIZADO}

Uma vez caracterizada a estrutura em rede como a mais adequada para sustentar o processo de aprendizado necessário à obtenção de ganhos competitivos em formações baseadas em cadeias de suprimento, principalmente quando estas estão relacionadas a CoPS -, cresce o interesse pela busca de mecanismos que possam acelerar e apoiar a criação de redes de aprendizado. Nesta seção, primeiramente são apresentados os argumentos que justificam a transformação de uma rede de firmas em uma rede de aprendizado e sua relevância. Em seguida, são expostos os mecanismos utilizados para a formação das redes e as dificuldades que precisam ser transpostas para sua consolidação.

\section{A transformação de uma rede de firmas em uma rede de aprendizado}

$O$ processo de aprendizado organizacional é um fenômeno estudado há muito tempo no campo das organizações. Considera-se que ele depende tanto de mudanças na base técnica da produção, como nos processos gerenciais que dão sustentação a essa base. É importante ressaltar que se deve examinar não apenas a adoção ou implementação de novas tecnologias no ambiente organizacional, mas também como as organizações desenvolvem estratégias, estruturas, processos de trabalho, estilos de liderança, comportamentos e culturas que lhes permitam obter desempenhos diferenciados em relação à concorrência.

O desempenho de alguns setores industriais japoneses, nas décadas de 1970 e 1980, foi fundamental para renovar o interesse nesse tipo de abordagem. Avaliou-se que as inovações organizacionais introduzidas nas empresas nipônicas foram as principais responsáveis pela performance diferenciada por elas apresentadas, sendo que o aspecto mais importante desse conjunto de inovações teria sido o estabelecimento de processos de melhorias contínuas.

Reforçou-se assim, por um lado, a convicção de que a renovação tecnológica, baseada na mera compra de equipamentos de base microeletrônica, por exemplo, não era uma resposta suficiente para a obtenção de um desempenho superior (Senge, 1990; Garvin, 1993; Leonard-Barton, 1995). Por outro lado, cresceu a atenção dada às organizações de aprendizado e reviveu-se o interesse pelos mecanismos que levam ao aprendizado organizacional.

Um primeiro problema que precisou ser contornado foi a necessidade de adequar o conceito de aprendizado a organizações, pois, originalmente, ele foi aplicado a indivíduos (Argyris e Schon, 1978) - afinal, são os indivíduos que aprendem, e não as organizações. A solução foi entender as organizações como ambientes adequados à troca de experiências e à criação de conhecimento. Em outras palavras, embora os indivíduos sejam o sujeito central do processo de aprendi- 
zado, são as organizações que garantem o contexto no qual ele ocorre. A elas cumpre a tarefa de desenvolver mecanismos que facilitem o processo interativo que leva ao aprendizado, incluindo a captura do saber tácito, aquele que não é formalizado, presente em todos os indivíduos e grupos.

O desenvolvimento de mecanismos de aprendizado organizacional passou a contar com o apoio de modelos que trataram de identificar e simplificar as relações entre os elementos envolvidos. O modelo de Kolb (1991) é um dos mais conhecidos. Nele, o aprendizado é visto como sendo cíclico, envolvendo uma combinação de experiência, reflexão, conceituação e experimentação. Não existe nada de automático na visão cíclica do processo. Uma boa dose de motivação é imprescindível para que ele seja iniciado. O papel das organizações torna-se, a partir desse modelo, mais claro: seriam elas que criariam estruturas, procedimentos, valores, comportamentos e interesses mais adequados ao desencadeamento de todas as etapas do ciclo.

A entrada das empresas nesse ciclo virtuoso de aprendizado encontra, todavia, barreiras consideráveis. Em primeiro lugar, uma empresa sozinha pode não encontrar motivação suficiente para aprender, tanto por encontrar-se isolada ou impermeável aos estímulos externos, quanto por falhar na interpretação desses estímulos. Em segundo, mesmo que a motivação esteja presente, as empresas não conseguem completar todo o ciclo por um motivo simples: elas normalmente estão acostumadas a acumular experiência e realizar experimentação, não dispondo de muito tempo, nem de hábito, para as atividades de reflexão e conceituação. Em terceiro, a estrutura de apoio pode ser inexistente ou incompleta, o que, na maioria das vezes, denota uma falta de vinculação do aprendizado com a estratégia. Essas barreiras resultam em um processo de aprendizado infreqüente, esporádico e não sustentável. Com isso, o conteúdo do aprendizado repete-se, não se beneficiando do avanço que a captura do saber tácito pode provocar (Bessant e Tsekouras, 1999b).

Embora seja importante o conhecimento existente sobre o processo de aprendizado organizacional, o interesse por redes de aprendizado decorre, fundamentalmente, de evidências oriundas de experiências internacionais. De fato, redes de aprendizado espalhamse não apenas por países europeus, mas por todo o mundo (Nadvi e Schmitz, 1994; Humphrey e Schmitz, 1996). O caso da rede de aprendizado na cadeia de

Figura 1 - Elementos Básicos de uma Rede de Aprendizado

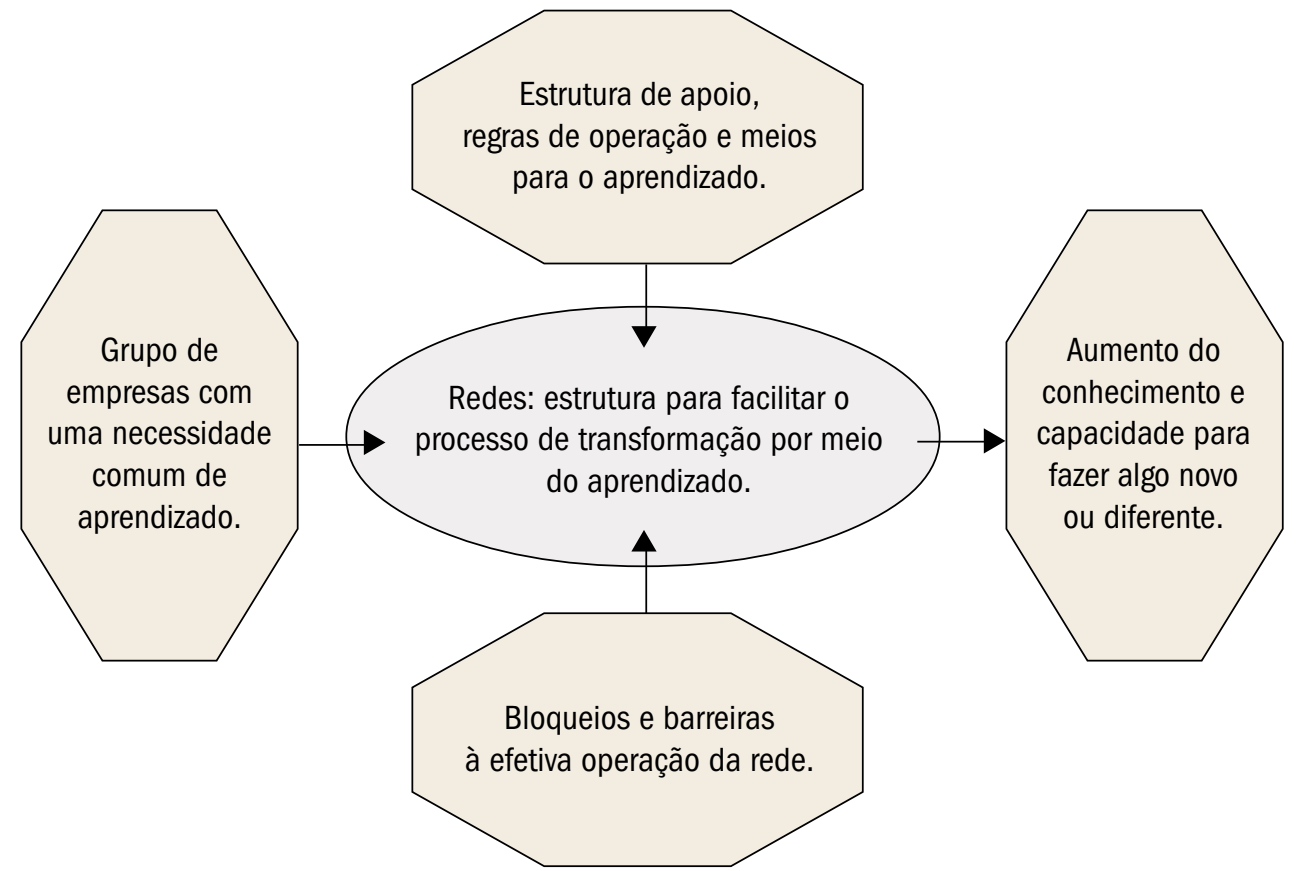

Fonte: Adaptado de Bessant e Tsekouras (1999b) 
têxteis da Terceira Itália é emblemático (Piore e Sabel, 1982). Ela foi se formando com o objetivo de compartilhar recursos usados em determinadas atividades, tais como compras e exportação. Daí evoluiu para o compartilhamento de outras experiências, chegando à criação de um centro de pesquisa cooperativo. Com isso, foi possível adicionar a dimensão tecnológica ao processo de aprendizado coletivo.

Apesar de não ter sido resultado de uma ação planejada, essa rede passou a ser vista como algo a ser adotado em outros locais, a partir de estímulos fornecidos pelos governos. A idéia subjacente é que, ao participar de um grupo que compartilha um mesmo objetivo, uma empresa individual pode se beneficiar de um espaço para a reflexão crítica sobre sua conduta a partir de diferentes perspectivas; pode ter acesso a modelos e práticas diferentes daquelas usadas internamente, abrindo, com isso, novas linhas de questionamento e experimentação. Adicionalmente, a reflexão em grupo reduz riscos e maximiza as oportunidades para experimentação de novos conceitos, modelos e práticas. O estabelecimento de redes teria, portanto, o potencial de maximizar as sinergias interorganizacionais.

A partir da análise dessas experiências internacionais e dos estudos teóricos sobre aprendizado organizacional, passou-se a definir rede de aprendizado learning network - como um conjunto de empresas, com algum grau de organização formalmente estabelecido, que se reúnem com o objetivo de aumentar o pool social de conhecimentos e informações (Bessant e Tsekouras, 1998, 1999a, 1999b).

\section{Implementação e operação de uma rede de aprendizado}

De acordo com a literatura revisada por Bessant e Tsekouras (1999b), existem alguns requisitos para o funcionamento de redes de aprendizado: i) estabelecer formalmente a rede; ii) ter um objetivo claro e uma definição sobre o tipo de aprendizado e conhecimento com que se irá trabalhar; iii) contar com uma estrutura de operação e com protocolos que estabeleçam regras de participação; iv) identificar, por meio de mapas de processos, o alvo para o aprendizado; v)

\section{Quadro 1 - Tipologia de redes de aprendizado}

\section{TIPO DE REDE \\ ALVO DO APRENDIZADO}

Profissional

Setorial

Cadeia de

Suprimento

Promovida pelo

Governo

Tópica chain.
Aumentar o conhecimento e as capacitações profissionais visando atingir a melhor prática na área.

Melhorar a competência em algum aspecto do desempenho competitivo de um setor. Por exemplo, conhecimento tecnológico.

Aumentar conhecimento sobre temas de interesse regional. Por exemplo, rede de pequenas e microempresas voltadas para exportação, difusão tecnológica e melhorias gerenciais etc.

Alcançar padrões de qualidade, custo e atendimento demandados por cliente(s) ao final de uma cadeia de suprimento - supply

Iniciativas nacionais ou regionais visando melhorar o desempenho competitivo de grupos de empresas, em termos de conhecimentos sobre novas tecnologias, exportação, marketing etc.

Aumentar o conhecimento sobre uma nova técnica em um campo particular e suas aplicações. Por exemplo, uma nova tecnologia de interesse comum de várias empresas.

\section{EXEMPLOS}

Rede organizada por entidade de categoria profissional.

Rede organizada por sindicato patronal, associação de indústria ou entidade de pesquisa voltada para um setor.

Cooperativas de aprendizado que podem levar à formação de clusters.

Rede de firmas que participam de uma cadeia de suprimento com grandes clientes finais.

Redes organizadas por agências regionais ou setoriais de desenvolvimento.

Clubes de "melhores práticas". 
escolher instrumentos de medidas que permitam verificar os resultados da operação da rede. Cumprir esses requisitos é fundamental para que bloqueios à efetiva operação da rede possam ser superados. A Figura 1 sintetiza os elementos básicos de uma rede de aprendizado até aqui apresentados.

Com base em diversas experiências, Bessant e Francis (1999) propõem uma tipologia de redes de aprendizado tendo como base o alvo de aprendizado de cada uma delas. Essa tipologia é apresentada no Quadro 1. É importante observar que, em alguns casos, a rede de aprendizado é uma das atividades desempenhadas por seu promotor/operador, como uma entidade de certa categoria profissional ou um órgão de representação de classe - sindicato patronal, por exemplo -, em paralelo às outras atividades comuns nesse tipo de instituição. Em tal tipologia, o papel do governo pode ser tanto de promoção e operação, como de incentivador da formação de redes a serem operadas por outros agentes.

A idéia de que uma rede de aprendizado pode ser resultado de uma iniciativa planejada pressupõe que haja uma organização por trás de sua operação. Essa organização tem como tarefa o gerenciamento de atividades e processos que contribuam para que se atin- ja a missão da rede. Seu principal papel é o de servir como estimuladora da integração dos membros e, ao mesmo tempo, coordenadora dos trabalhos que levem ao compartilhamento do aprendizado e do conhecimento.

Nesse sentido, descrevem-se, no Quadro 2, oito processos considerados centrais na operação de uma rede, que devem receber especial atenção da organização responsável por seu funcionamento, pois a eficácia da rede dependerá da maneira como eles forem gerenciados.

Sintetizando, convém reafirmar alguns pontos e apresentar outros, até então não mencionados, que, de acordo com Bessant e Tsekouras (1999b), devem ser considerados na constituição e operação de uma rede de aprendizado.

- É de fundamental importância que a rede estabeleça uma meta clara e factível, que seja compartilhada por todos os participantes. Isso torna o trabalho de promoção do aprendizado mais focado, facilita a medição dos melhoramentos alcançados e mantém a motivação dos participantes.

- Os critérios para participação na rede devem ser claros. A princípio, uma rede deve se manter aberta à participação de novos membros, desde que eles en-

\section{Quadro 2 - Processos centrais na operação de uma rede}

\section{PROCESSOS}

Criação da rede

Tomada de decisão

Resolução de conflitos

Processamento de informações

Obtenção de conhecimento

Motivação/compromisso

Compartilhamento dos custos e benefícios

Integração

\section{PROPÓSITOS}

Definir como os participantes serão atraídos e como serão mantidos.

Estabelecer como, onde, quando e quem será o responsável pelas decisões.

Fixar os mecanismos de resolução de conflitos, quem irá implementá-los e como.

Gerenciar o fluxo de informações a circular entre os participantes.

Articular 0 acesso e a obtenção de conhecimento relevante para a rede e torná-lo disponível para os participantes.

Desenvolver mecanismos que assegurem a motivação dos participantes e o compromisso com seus objetivos.

Definir como serão compartilhados os benefícios e os eventuais custos e riscos associados ao funcionamento da rede.

Estipular como as relações entre os participantes da rede serão construídas e mantidas, tendo em vista a necessária integração entre eles. 
quadrem-se nos limites estabelecidos. A definição dessa fronteira ajuda a focar os objetivos e as metas de aprendizado.

- O modelo de estrutura organizacional a ser adotado depende do tipo de rede e do fluxo de informação que se quer estabelecer e enfatizar. Quando o fluxo de informação é mais complexo, envolvendo comunicação em dois ou mais sentidos, é necessária uma estrutura mais bem definida e formalizada.

- A definição do papel da coordenação é crucial. Ela é responsável pela organização dos eventos, edição de boletins e, acima de tudo, pela manutenção da motivação dos membros. Uma atividade crítica é a seleção de intermediários e consultores que irão promover o aprendizado interativo dos participantes.

- A caracterização do tipo de aprendizado que será promovido possui sérias implicações para o funcionamento da rede. O aprendizado pode ter diferentes focos, desde a familiarização com uma nova regulação, passando pela difusão de uma nova técnica, até formas mais complexas, como a adoção de novas filosofias gerenciais. Estruturas de operação, métodos e mecanismos diferem de acordo com o tipo de aprendizado que se quer promover.

- O conteúdo do processo é diferente para cada tipo de aprendizado. Cumpre, portanto, estabelecer de forma clara o plano que levará à difusão das técnicas e dos métodos que resultem em efetiva melhoria do desempenho. Nessa área, não é recomendável criar novas técnicas ou metodologias, mas selecionar, entre as existentes, aquelas que estarão disponiveis para os participantes.

- A motivação inicial para que as empresas participem da rede é de crucial importância. Essa motivação pode vir de mudanças no meio ambiente, a exemplo de desregulamentação de mercados e/ou derrubada de alíquotas de importação - mudanças que devem ser usadas pela coordenação da rede como uma das justificativas para um esforço coletivo. Campanhas de conscientização sobre a ameaça de desaparecimento de empresas devido às novas condições de concorrência, realização de benchmarkings e formatação coletiva de programas de fomento industrial a serem pleiteados ao governo são exemplos de mecanismos para atrair e manter a participação.

- A identificação dos recursos necessários ao funcionamento da rede e como eles serão mobilizados é outro ponto importante. O planejamento deve especificar os recursos humanos, financeiros e técnicos que serão necessários para que a rede aconteça.
- A coordenação da rede deve, essencialmente, buscar a facilitação do processo de aprendizado. Ela não deve se envolver diretamente com consultoria, nem em diagnósticos das empresas participantes. Seu papel é fazer com que essas empresas definam suas necessidades de aprendizado, bem como tornar disponíveis os meios para o atendimento dessas necessidades.

- Os critérios de mensuração do desempenho da rede devem ser claramente estabelecidos e monitorados, o que facilitará a manutenção da motivação e, conseqüentemente, da participação.

- Existem bloqueios e barreiras que devem ser identificados e evitados ao longo do processo. Perda de motivação, dificuldades de comunicação, comportamento arredio de indivíduos-chave e resistência à mudança encontram-se entre os mais freqüentes.

Por meio da descrição e análise do processo de criação de uma rede de aprendizado no país, realizadas a seguir, será possível revisar os principais temas abordados nas seções anteriores.

\section{MAXPETRO: UMA REDE DE APRENDIZADO EM FORMAÇÃO}

A Maxpetro é uma rede de aprendizado cujos participantes fazem parte da cadeia de suprimento da indústria de petróleo no Brasil. Essa rede é uma iniciativa da Onip (Organização Nacional da Indústria do Petróleo), uma organização não-governamental que tem por missão maximizar os benefícios sociais e econômicos dos novos investimentos no setor de petróleo no país. Nessa iniciativa, a Onip conta com a colaboração técnica da Universidade Federal da Bahia e da University of Brighton-Inglaterra e financiamento do CTPetro/Finep. Os principais passos metodológicos utilizados para a implementação e operacionalização da rede serão explicitados a seguir.

A principal motivação para a proposição dessa rede e o interesse de empresas nela ingressarem vinculamse ao atual cenário da indústria brasileira de petróleo, no qual se combinam a liberalização da economia doméstica, a globalização produtiva, tecnológica e financeira, as exigências da Organização Mundial do Comércio e, principalmente, a flexibilização do monopólio que existia. Firmas que até então operavam isoladas da competição internacional, fornecendo, basicamente, para um único comprador - a Petrobrás -, passaram a ser rapidamente confrontadas com a necessidade de aproximar seus níveis de 
eficiência aos de seus competidores internacionais.

Esse cenário traz desafios e, ao mesmo tempo, oportunidades para as empresas nacionais que operam na cadeia de suprimentos para a atividade petrolífera. Estima-se que, no período de 2001 a 2010 , cerca de US\$ 90 bilhões sejam investidos pela Petrobrás, por seus parceiros e novos entrantes nas atividades de exploração, produção (E\&P) e abastecimento de petróleo e gás. Qual a parcela desses investimentos a ser direcionada para a aquisição de materiais, equipamentos e contratação de serviços no território nacional? A resposta, assumindo a existência de uma plena e justa oportunidade para todos, dependerá da capacidade das empresas nacionais mostrarem-se competitivas.

O processo de produção de petróleo offshore exige o fornecimento de materiais, equipamentos e serviços altamente complexos e especificados por projetos, afastando os supridores dos tradicionais esquemas de produção em série. Em tal sistema complexo - CoPS - , as firmas não atuam isoladamente. Elas organizam-se em redes verticais do tipo piramidal. Nessa estrutura vertical, as companhias de petróleo assumem um papel claramente coordenador, em função de seu poder de compra e dos termos de cooperação estabelecidos por elas. Em seguida, vêm os main contractors - geralmente firmas de engenharia; no caso da indústria de petróleo no Brasil, a Odebrecht e a Marítima são exemplos de main contractors que prestam serviços de construção de plataformas para a Petrobrás -, que aparecem como fornecedores de bens e serviços críticos e, ao mesmo tempo, como demandantes de bens e serviços de diversos outros supridores.

Nesse contexto, a rede de firmas que caracteriza o complexo sistema de atividades na E\&P offshore teria, em princípio, muito a ganhar com a formação de uma rede de aprendizado, sendo que os cenários externo e interno, há pouco mencionados, apresentamse como o principal motivador para a rede Maxpetro, que foi concebida para cumprir três fases.

1. Estabelecendo a Rede de Aprendizado. A Onip foi encarregada da identificação e mobilização das empresas interessadas em participar da rede. Em seguida, foi definida a utilização da técnica de benchmarking como meio de conscientizar as empresas para a necessidade de aprendizado. Essa técnica foi usada como uma ferramenta inicial por dois motivos. Em primeiro lugar, por permitir comparar, entre as empresas da rede Maxpetro - benchmarking nacional -, e entre elas e as internacionais - benchmarking internacional -, indicadores de desempenho e práticas organizacionais e tecnológicas utilizadas. Com isso, existiriam condições de montar um diagnóstico da situação competitiva da cadeia de suprimento. Em segundo lugar, porque os resultados do benchmarking serviriam como motivadores para as empresas entrarem em um processo de aprendizado individual e coletivo, visando a uma melhoria de seus processos e produtos, assim como desenvolvimento e implementação de planos de ação para alcançar e manter o nível de desempenho desejado.

Para a realização do benchmarking foi necessário, primeiramente, definir os indicadores e as práticas tecnológicas e organizacionais mais relevantes para efeito de comparação. Chegou-se a essa definição por meio de consulta realizada junto às empresas brasileiras participantes da rede, em dois workshops. Isso feito, montou-se um questionário para levantar informações, junto a essas empresas, que permitissem a construção dos indicadores já definidos e a identificação das práticas por elas usadas. Com base nas respostas, elas puderam comparar seus desempenhos.

Em um outro workshop, foram expostos e debatidos os resultados do benchmarking internacional. A partir de informações coletadas junto a três fontes distintas de dados, montou-se indicadores e práticas passíveis de comparação com os dados do benchmarking nacional. A primeira dessas fontes foi a Industrial Capability Database, do Department of Trade and Industry do Reino Unido, que contém 6 mil entradas com o nome da empresa, seu setor de atividade, linha de produtos e mercado ao qual pertence. Selecionaram-se 44 empresas, de 12 segmentos, que guardam correspondência com os das empresas da Maxpetro. A segunda pertence à First Point Assessment Ltd - FPAL -, uma organização independente de creditação de fornecedores para a indústria de petróleo, localizada na Escócia, que trabalha para 40 operadoras e main contractors e que possui mais de 2 mil supridores em seu cadastro. A última foi obtida com a aplicação de um questionário junto a 29 empresas estrangeiras, presentes na Feira Internacional Rio Oil \& Gas, realizada no Rio de Janeiro em 2000 , sendo 20 de bens -11 norte-americanas e nove européias - e nove de serviços - cinco norte-americanas e quatro européias.

2. Planejamento do Desenvolvimento da Rede de Aprendizado. O produto esperado dessa fase é a definição do desenho organizacional mais adequado para esse tipo de rede, bem como os instrumentos e méto- 
dos a serem utilizados para que as empresas possam internalizar as melhores práticas. Como visto, a experiência internacional indica que é possível identificar mecanismos, a serem usados pelas empresas, que as levem a buscar uma melhoria contínua de seus procedimentos.

3. Operação da Rede de Aprendizado. Concluída a fase acima, a rede Maxpetro estaria implantada e, a partir daí, a Onip assumiria integralmente sua coordenação, uma vez que sua manutenção e a disponibilização de métodos e técnicas voltados para a melhoria do desempenho das empresas são tarefas permanentes, que se confundem com a própria missão dessa organização.

Após mais de um ano do início desse processo, as principais dificuldades podem ser assim resumidas:

- Embora tenham participado dos primeiros workshops, tanto as companhias de petróleo quanto as main contractors não continuaram na rede. Aparentemente, essas empresas avaliaram que o projeto poderia beneficiar mais a seus fornecedores que a elas próprias. Muito possivelmente, tal avaliação deve ter sido baseada na pressuposição de que elas já eram empresas de classe mundial e que seus obstáculos competitivos situam-se no campo sistêmico. Ainda que isso possa ser verdade, a participação dessas empresas, que estão no final da cadeia de suprimento e que exercem a governança do processo, é indispensável para o sucesso de uma rede desse tipo. Isso porque a Maxpetro precisa trabalhar também com práticas interorganizacionais. Ou seja, aquelas práticas que contribuem para a redução dos custos de transação ao longo da cadeia e que, para serem implementadas, dependem de negociações envolvendo todos seus elos, uma vez que atingem diretamente as relações cliente/fornecedor, a exemplo de padronização de especificações técnicas e contratos. A grande dificuldade é fazer com que tais empresas percebam os ganhos advindos do fortaleci- mento dos fornecedores locais, a despeito de possuírem fornecedores externos de classe mundial.

- De modo geral, as empresas tendem a trazer à discussão problemas relacionados com os aspectos sistêmicos da competitividade, notadamente os associados às questões tributária, monetária (juros) e de infra-estrutura. Embora se reconheça que esses problemas causam significativamente impacto na capacidade das empresas competirem, eles não são objeto de uma rede de aprendizado. Com isso, observa-se uma tendência, mesmo entre empresas que estão longe de poderem se considerar de classe mundial, de concluírem que "não tem muito o que aprender, pois, do ponto de vista empresarial, já são suficientemente competitivas".

- O fato de as empresas participantes da Maxpetro serem bastante heterogêneas, em relação ao tamanho, base tecnológica, tipos de produtos, estruturas de mercado nas quais se inserem etc., fez com que os resultados comparativos do benchmarking nacional fossem prejudicados. A ampliação e uma maior homogeneização da base de comparação podem contornar esse problema.

- Houve sérias dificuldades para a obtenção de dados que possibilitassem a realização do benchmarking internacional. Não existiam bases de dados, já prontas, em formatos que permitissem comparações com todos os indicadores e práticas levantados junto às empresas da Maxpetro. Mesmo usando três bases de dados diferentes, só foi possível comparar seis indicadores do benchmarking nacional, que no total trabalhou com 17.

- Ocorreram alguns problemas de comunicação com as empresas participantes. Na verdade, mesmo contando com uma base reduzida, a idéia de uma rede de aprendizado e seus benefícios parece que não foi adequadamente transmitida e/ou captada por todas elas. A Figura 2 apresenta uma caracterização de redes

Figura 2 - Características das Redes de Aprendizado

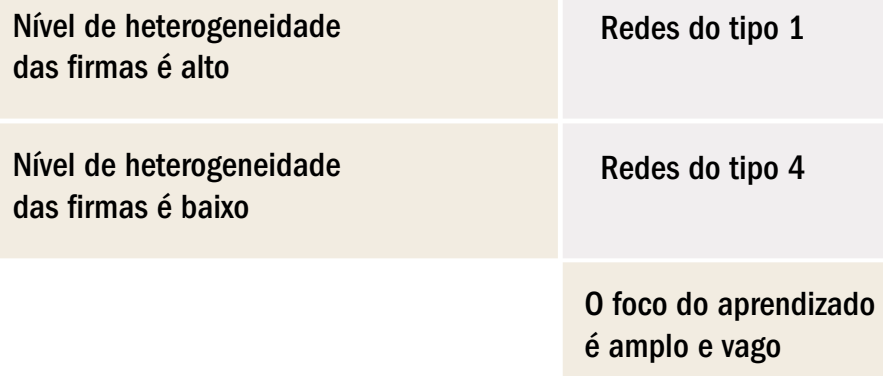

Redes do tipo 1

Redes do tipo 4

0 foco do aprendizado é amplo e vago

Redes do tipo 2

Redes do tipo 3

0 foco do aprendizado é claro e bem definido 
de aprendizado com base em duas variáveis: heterogeneidade das firmas participantes e foco do aprendizado. Analisando-se o caso Maxpetro, pode-se dizer que o desafio dessa rede é migrar de uma rede do tipo 1 para uma do tipo 2 , que possui foco de aprendizado claro e bem definido.

\section{CONSIDERAÇÕES FINAIS}

Neste artigo, procura-se demonstrar que, devido às suas características, os Sistemas Complexos de Produção (CopS) têm na rede de firmas seu arranjo interorganizacional típico. Em vista disso, torna-se necessário aprofundar a investigação sobre os CoPS e as redes de firmas, para que se possa enriquecer o entendimento sobre a dinâmica concorrencial e as estratégias empresariais desse tipo de sistema de produção. Do ponto de vista teórico, a unidade básica de análise para a compreensão desses temas deixa de limitar-se à firma individual e passa a envolver as redes de firmas.

Nos Sistemas Complexos de Produção, a colaboração na elaboração de propostas para licitações e na execução de projetos é requisito básico para o bom desempenho de seus produtores. Como a competição dá-se entre projetos e não entre firmas individuais, melhorias isoladas em uma firma individual, apesar de importantes, podem ter apenas um pequeno efeito na competitividade e performance do projeto. Desse modo, uma efetiva competitividade requer a otimização de procedimentos do conjunto de firmas envolvidas com tais projetos. Ou seja, a eficiência coletiva sobrepõe-se à eficiência individual.

A busca por uma maior eficiência coletiva, dada a freqüente heterogeneidade dos agentes em termos de capacitação produtiva, tecnológica e organizacional, termina por estimular essa rede de firmas a transformar-se em uma rede de aprendizado, em um pool social de conhecimentos e informações que circulam entre seus membros, gerando, potencialmente, fortes externalidades positivas e permitindo a obtenção de ganhos competitivos.

Essa transformação não é trivial, por vários motivos: o aprendizado em rede não é uma característica natural de qualquer tipo de cadeia de suprimentos; o conhecimento existente sobre redes de aprendizado é ainda muito precário; e as evidências sobre seus resultados são insuficientes para que se afirmem verdades inequívocas sobre seu papel na construção de uma autêntica competitividade. Apesar disso, exemplos espalhados ao redor do mundo apontam para a emergência dessa nova forma de aprendizado coletivo como instrumento para alavancar o desempenho de conjuntos de empresas dispostas ao longo de distintas cadeias de suprimento.

No entanto, caso deseje-se efetivamente utilizá-las como um instrumento para tal fim, e isso parece perfeitamente justificável, certos cuidados precisam ser tomados quando do planejamento, constituição e operacionalização dessas redes de aprendizado. Ainda que se tenha em conta o perigo de generalizações a partir de um caso particular, a experiência da rede Maxpetro permite que se façam algumas observações.

Em primeiro lugar, a cadeia de suprimento da indústria de petróleo, particularmente o fornecimento de sistemas de produção offshore, reúne as características que a teoria ressalta como essenciais para a constituição de redes de aprendizado: são Sistemas Complexos de Produção (CoPS), cujo desempenho competitivo é fortemente influenciado pela natureza da colaboração que se estabelece ao longo da cadeia. Mesmo assim, a análise da implantação da Maxpetro aponta para o fato, de fundamental importância, de que a rede tem de ter um propósito claro, que se traduza em uma meta a ser atingida durante o processo de aprendizado.

Em segundo lugar, raramente essas redes surgem espontaneamente. Por isso, é essencial que se crie uma estrutura - que pode tender ao virtual -, que se definam os recursos e os mecanismos que serão utilizados para implantar e sustentar a rede, e que se tente prever, com base em outras experiências, as inevitáveis dificuldades que surgirão no planejamento e na operacionalização. Esses cuidados, somados a uma permanente busca por novas abordagens para o processo de aprendizagem organizacional, são imprescindíveis para a obtenção e manutenção de efetivos ganhos competitivos.

Artigo recebido em 09/08/2001. Aprovado em 06/05/2002.

\section{REFERÊNCIAS BIBLIOGRÁFICAS}

ARGYRIS, C., SCHON, D. Organizational learning: a theory of action perspective. Reading : Addison-Wesley, 1978.

ARROW, K. J. Rationality of self and others in an economic system. Journal of Business, v. 59, n. 4, p.385-99, 1986. 
BESSANT, J., FRANCIS, D. Using learning networks to improve manufacturing competitiveness. Technovation, v. 19, p. 373-81, 1999.

BESSANT, J., TSEKOURAS, G. Learning networks. Centrim. Brigthon: University of Brighton, 1998. Working paper.

BESSANT, J., TSEKOURAS, G. Learning about learning networks. Centrim. Brigthon : University of Brighton, 1999(a). Working paper.

BESSANT, J., TSEKOURAS, G. Developing learning networks. Centrim. Brigthon : University of Brighton, 1999(b). Working paper.

BRITTO, J. Redes de firmas e eficiência técnico-produtiva: uma análise crítica da abordagem dos custos de transação. In: ENCONTRO NACIONAL DE ECONOMIA, 22., 1994, Florianópolis. Anais... Brasília : ANPEC, 1994. V.1, p. 120-39.

CHANDLER, A. D. Scale and scope: the dynamics of industrial capitalism. Cambridge : Harvard University Press, 1990.

CHANDLER, A. D. What is a firm? A historical perspective. European Economic Review, North-Holland, 36, p. 483-92, 1992.

DAVIES, A. The life cycle of a complex product system. International Journal of Innovation Management, v. 1, n. 3, p.22956, 1997.

DOSI, G., TEECE, D., WINTER, S. Toward a theory of corporate coherence: preliminary remarks. In: DOSI, G. et al. (Eds.). Technology and enterprise in a historical perspective. Oxford : Clarendon Press, 1992.

GARVIN, D. Building a learning organization. Harvard Business Review, p. 78-91, July/Aug. 1993.

HOBDAY, M. Product complexity, innovation and industrial organization. Research Policy, 26, p. 689-710, 1998.

HUMPHREY, J., SCHIMITZ, H. The triple C approach to local industrial policy. World Development, v. 24, n. 12, p. 1859-77, 1996.

KOLB, D. Organizational behaviour. New York : Prentice Hall, 1991.

LEONARD-BARTON, D. Wellsprings of knowledge: building and sustaining the sources of innovation. Boston: Harvard Business School Press, 1995.
MAZZALI, L., COSTA, V. M. H. M. As formas de organização em rede: configuração e instrumento. Revista de Economia Politica, São Paulo, v. 17, n. 4, p. 121-39, 1997.

Miller, R., HOBDAY, M., LEROUX-DEMERS, T., OLLEROS, X. Innovation in complex system industries: the case of flight simulators. Industrial and Corporate Change, v. 4, n. 2, p. 363-400, 1995.

MOWERY, D. C., ROSENBERG, N. Technical change in the commercial aircraft industry. In: Inside the black box: technology and economics. Cambridge: Cambridge University Press, 1982.

NADVI, K., SCHIMITZ, H. Industrial clusters in less developed countries: review of experiences and research agenda. Brighton : IDS/University of Sussex, 1994. Mimeo.

NELSON, R., WINTER, S. An evolutionary theory of economic change. Cambridge : Harvard University Press, 1982.

PENROSE, E. The theory of the growth of the firm. New York: John Willey \& Sons, 1959.

PIORE, M., SABEL, C. The second industrial divide. New York : Basic Books, 1982.

PONDÉ, J. L. Coordenação e aprendizado: elementos para uma teoria das inovações institucionais nas firmas e nos mercados. 1993. Dissertação (Mestrado em Economia) - Instituto de Economia, Universidade de Campinas.

RICHARDSON, G. B. The organization of industry. Economic Journal, p. 883-96, Sept. 1972.

SENGE, P. The fifth discipline. New York: Doubleday, 1990.

TEECE, D. J. Technological change and the nature of the firm. In: DOSI, G. et al. (Eds.). Technical change and economic theory. London: Pinter Publishers, 1988.

TEECE, D. J. Design issues for innovative firms: bureaucracy, incentives and industrial structure. In: __ The dynamic firm: the role of technology, strategy, organization and regions. Oxford : Oxford University Press, 1998.

WILLIAMSON, O. E. Las instituciones economicas del capitalismo. Mexico : Fondo de Cultura Economica, 1985. 